Supporting information for

\title{
Tungsten oxide nanodots exhibits mild interactions with WW and SH3 modular protein domains
}

\author{
Wei Song ${ }^{\mathrm{a},}$, Zhifeng Jing ${ }^{\mathrm{b} \neq 1}$, Lijun Menga ${ }^{\mathrm{a}}$, and Ruhong Zhou ${ }^{\mathrm{a}, \mathrm{b}}$ * \\ a Institute of Quantitative Biology, Zhejiang University, Hangzhou 310027, China \\ ${ }^{\mathrm{b}}$ IBM Thomas J. Watson Research Center, Yorktown Heights, NY 10598, USA \\ ‡ These authors contribute equally \\ *Corresponding author, E-mail: rhzhou@zju.edu.cn
}

${ }^{1}$ Current address: Department of Biomedical Engineering, The University of Texas at Austin, Austin, Texas 78712, United States 


\section{Convergence analysis.}

The evolution of contact area between the protein domain and WO3 or PRM is shown in Fig. S1-S4. In most of the simulations, the binding events occur before $100 \mathrm{~ns}$ and there are multiple binding/unbinding events in most of the simulations. In one WW-domain competitive binding simulation and two SH3-domain competitive binding simulations, there are signs of irreversible binding between $\mathrm{WO}_{3-\mathrm{x}}$ and the protein domains towards the end of the simulations. However, in all these cases, PRM binds to the key residues and $\mathrm{WO}_{3-\mathrm{x}}$ is far from the key residues, i.e. $\mathrm{WO}_{3-\mathrm{x}}$ does not interfere with the binding between PRM and protein domains.

The binding free energies calculated from the first $200 \mathrm{~ns}$ trajectories and from the entire $600 \mathrm{~ns}$ trajectories are shown in Fig. S5. The results of the first 200 ns are not statistically different from the results of the entire trajectory. The binding free energy with PRM is consistently lower than that with $\mathrm{WO}_{3-\mathrm{x}}$. It should be noted that although the statistical errors are relatively large compared to the difference between $\mathrm{WO}_{3-\mathrm{x}}$ and PRM, the binding of $\mathrm{WO}_{3-\mathrm{x}}$ and of PRM are correlated (see Fig. S2 and S4), and therefore Fig. S5 cannot be used to evaluate the statistical significance of the difference between $\mathrm{WO}_{3-\mathrm{x}}$ and PRM.
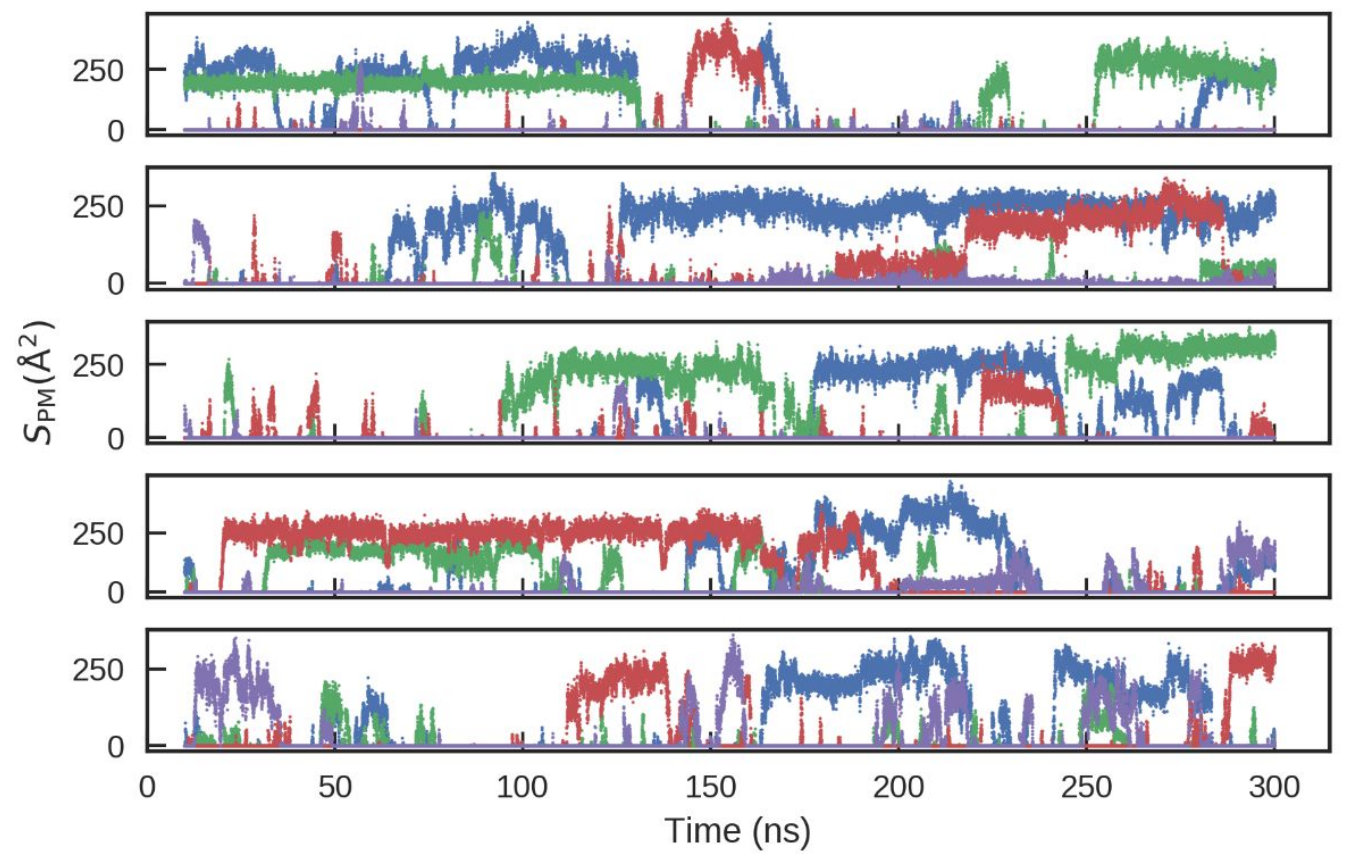

Figure S1. Evolution of contact area between $\mathrm{WO}_{3-\mathrm{x}}$ and $\mathrm{WW}$ domain in the intrinsic binding simulations. 


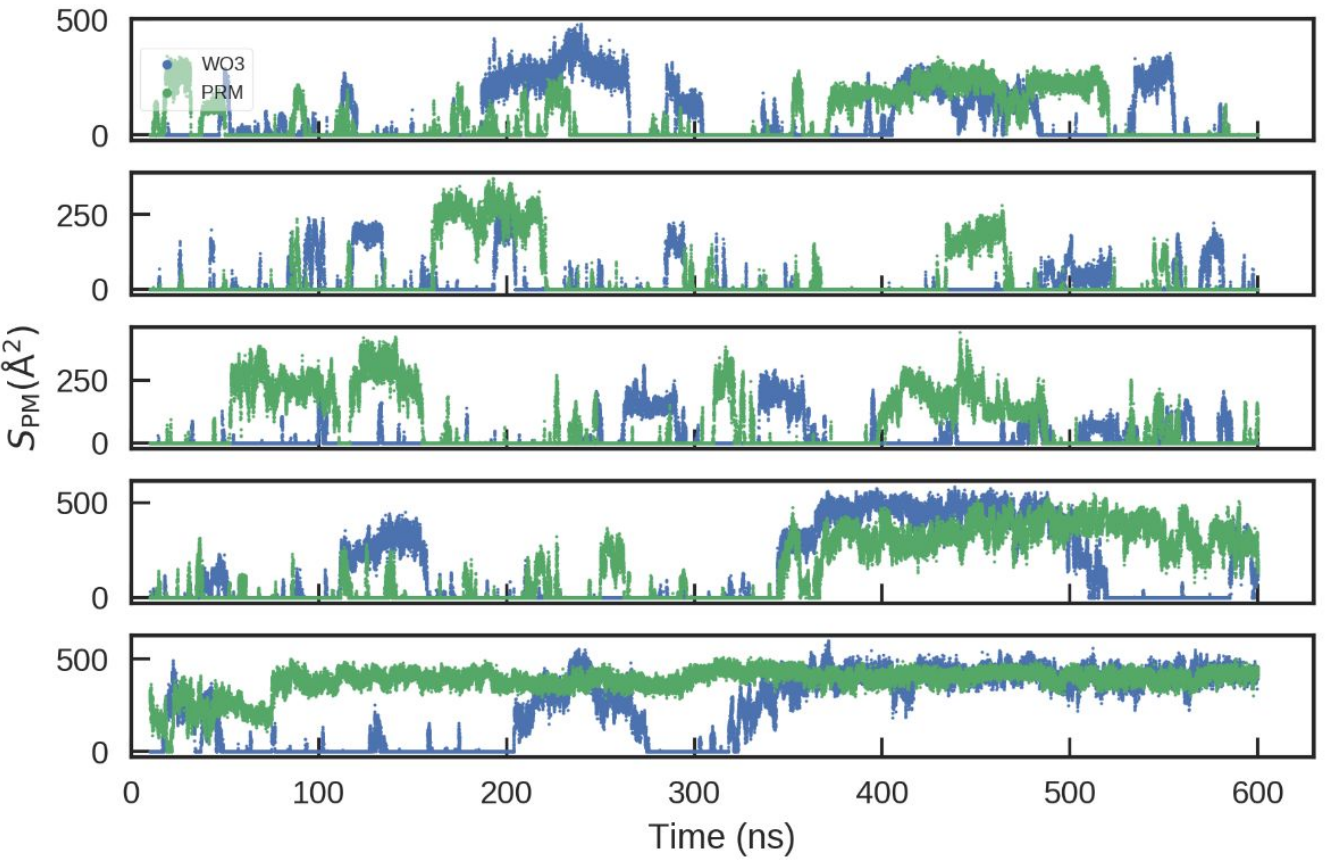

Figure S2. Evolution of contact areas between $\mathrm{PRM} / \mathrm{WO}_{3-\mathrm{x}}$ and $\mathrm{WW}$ domain in the competitive binding simulations.
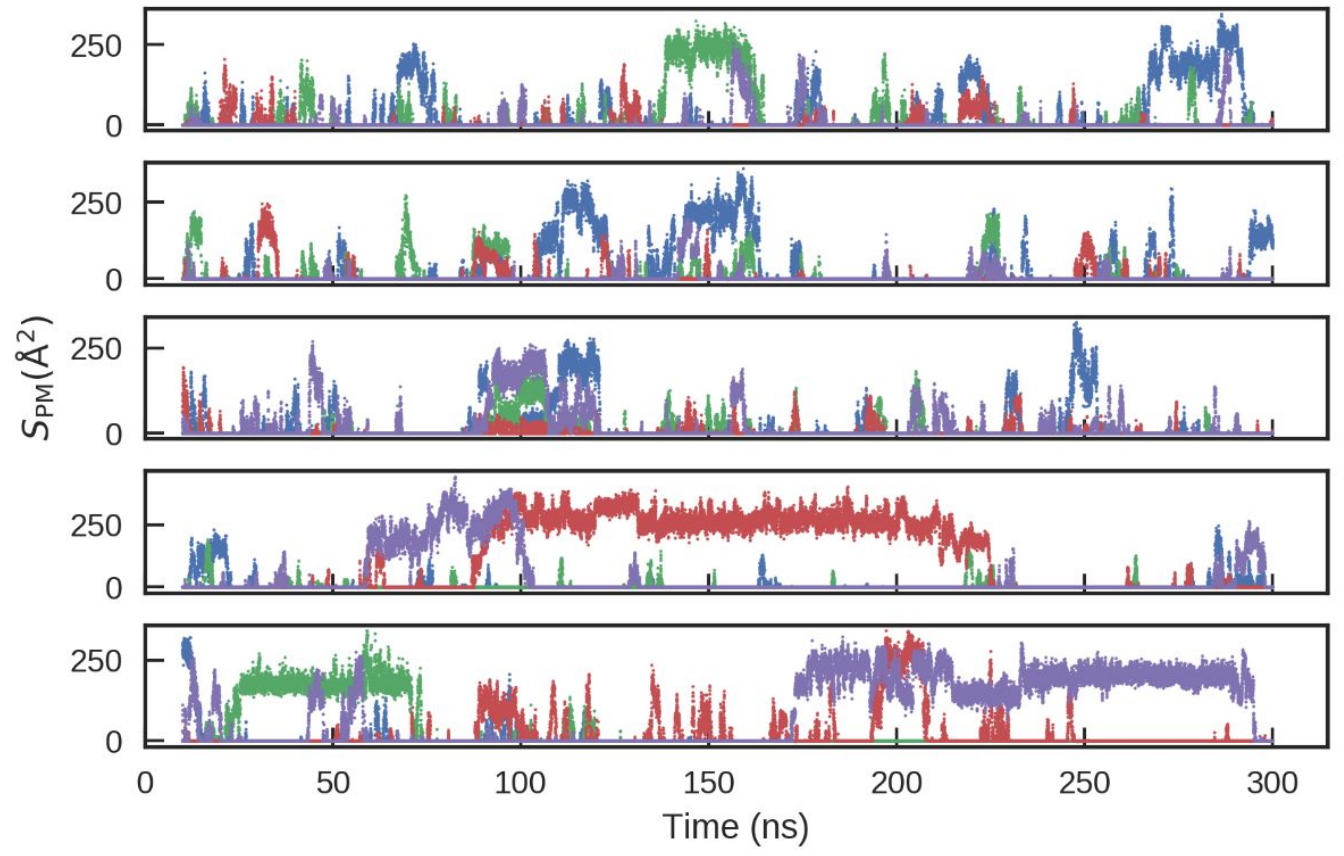

Figure S3. Evolution of contact area between $\mathrm{WO}_{3-\mathrm{x}}$ and $\mathrm{SH} 3$ domain in the intrinsic binding simulations. 

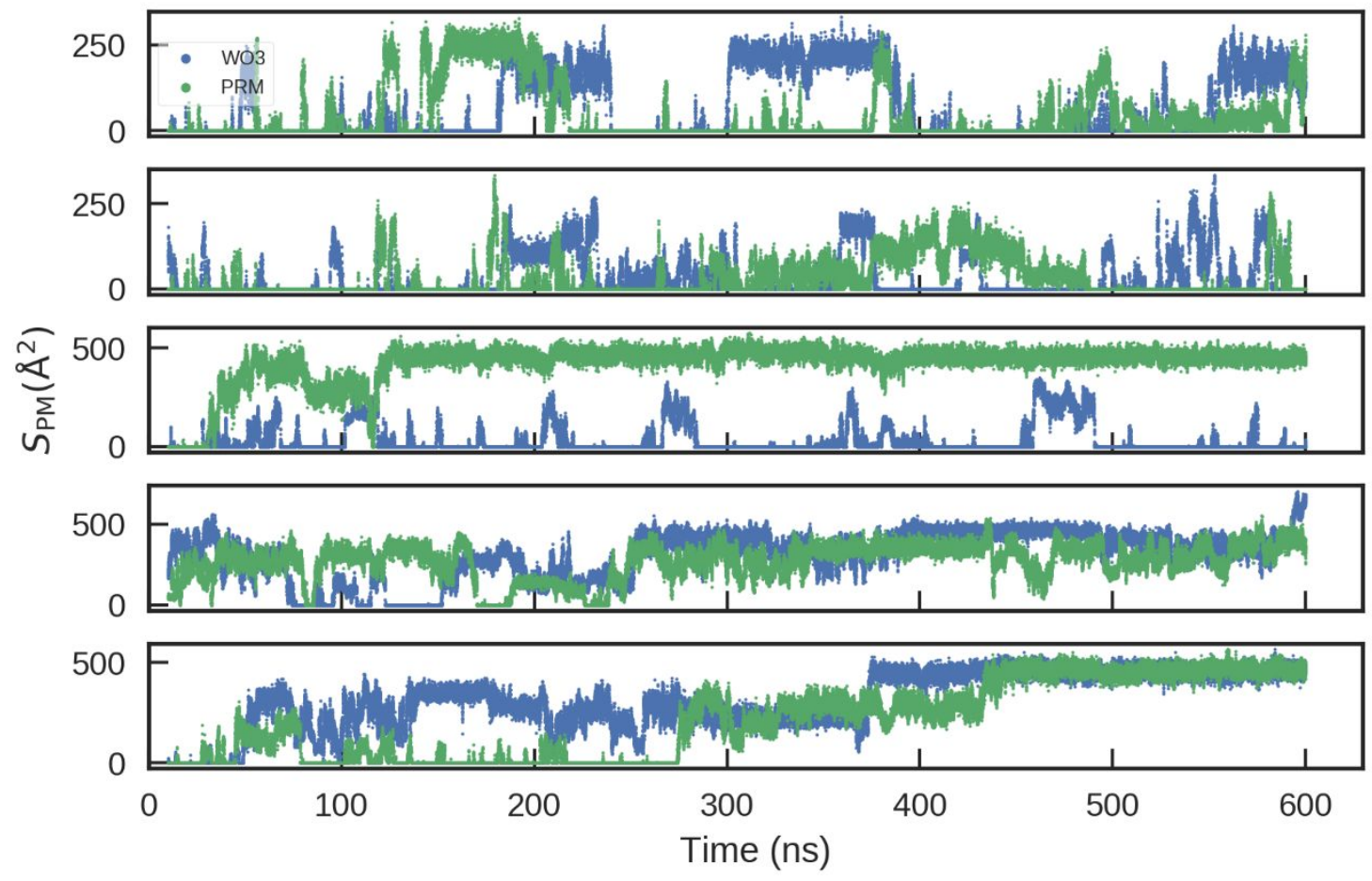

Figure S4. Evolution of contact areas between $\mathrm{PRM} / \mathrm{WO}_{3-\mathrm{x}}$ and $\mathrm{SH} 3$ domain in the competitive binding simulations.

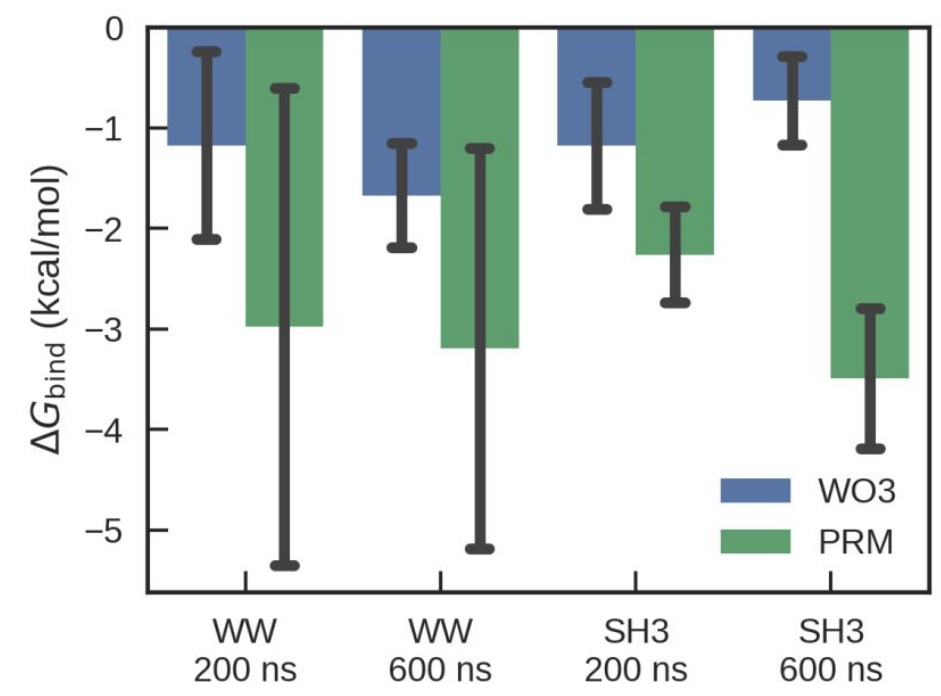

Figure S5. Binding free energies calculated from the competitive binding simulations. 